\title{
Detrás del Ecce Homo: retos y oportunidades para la conservación del patrimonio rural español en un contexto de despoblación
}

En el verano de 2012, la fallida restauración de un fresco en el santuario de Misericordia de Borja (Zaragoza) se convirtió en un fenómeno viral. Medios de todo el mundo publicaron las imágenes del Ecce Homo antes y después de la intervención de Cecilia Giménez, una octogenaria pintora aficionada, colaborada habitual en el mantenimiento del santuario. Cautivados por la historia y por la naturaleza cómica del resultado, la mayoría de los medios pasaron por alto que Giménez intervino en el fresco en unas condiciones culturales, socioeconómicas y demográficas muy concretas, movida tanto por un fuerte sentimiento religioso como por un entendimiento colectivo del patrimonio cultural que es común en el medio rural español. Como ella, y también con mejor o peor fortuna, miles de habitantes de pequeños pueblos (especialmente mujeres) se ocupan regularmente de la conservación y el mantenimiento del patrimonio rural, tanto religioso como civil, tanto material como inmaterial. Sin embargo, la segunda gran oleada de despoblación rural que está experimentando la España interior pone en serio peligro este modelo de cuidado. Mirar más allá del Ecce Homo implica no solamente reconocer y evaluar este fenómeno, sino también entender sus posibles implicaciones y las oportunidades que pueden surgir a nivel político y legislativo para abordarlo.

Alberto Sánchez Sánchez | doctorando de la University of California, Berkeley

URL de la contribución <www.iaph.es/revistaph/index.php/revistaph/article/view/4409>

El siete de agosto de 2012, el Centro de Estudios Borjanos publicó en su blog una entrada denunciando la fallida restauración de un pequeño fresco situado en el interior del santuario de la Virgen de Misericordia, a unos cinco kilómetros del centro urbano de Borja (Zaragoza). La publicación, que llevaba por título "Un hecho inclasificable," pasó más o menos desapercibida hasta que una periodista del Heraldo de Aragón se hizo eco del caso dos semanas más tarde, llevando las imágenes del antes y el después de la intervención a la portada del diario, tanto en su versión impresa como digital. Ni la entrada en el blog del Centro de Estudios Borjanos ni la noticia en Heraldo de Aragón mencionaban explícitamente a la autora de la restauración, pero pronto otros medios de comunicación empezaron a sugerir que se trataba de una mujer octogenaria, pintora aficionada y colaboradora habitual en el mantenimiento del santuario. Cautivados por la historia y por la innegable naturaleza cómica del resultado, medios de todo el mundo publicaron las fotografías del fresco del Ecce Homo de Borja, bromeando sobre las buenas intenciones y la falta de conocimientos técnicos de la fallida restauradora, Cecilia Giménez. Lo que los medios de comunicación no recogieron es que Giménez trataba de ayudar en unas condiciones culturales, socioeconómicas y demográficas muy concretas, movida tanto por un fuerte sentimiento religioso como por un entendimiento colectivo del patrimonio cultural que es común en el medio rural español.

A pesar de su falta de conocimientos técnicos, Giménez había intervenido ya varias veces en el fresco y, junto con otros miembros de la pequeña comunidad que vive temporal o permanentemente en la pedanía en torno al santuario de la Virgen de Misericordia, se ocupaba del mantenimiento diario del templo. Más allá del carácter jocoso de la historia que los medios de comunicación celebraron de forma acrítica, el caso del Ecce Homo sirve para ilustrar cómo son los habitantes de pequeños municipios, y especialmente las mujeres, quienes se ocupan regularmente de la conservación y sostenimiento del patrimonio rural, tanto religioso como civil, tanto material como inmaterial. Si la historia del Ecce 


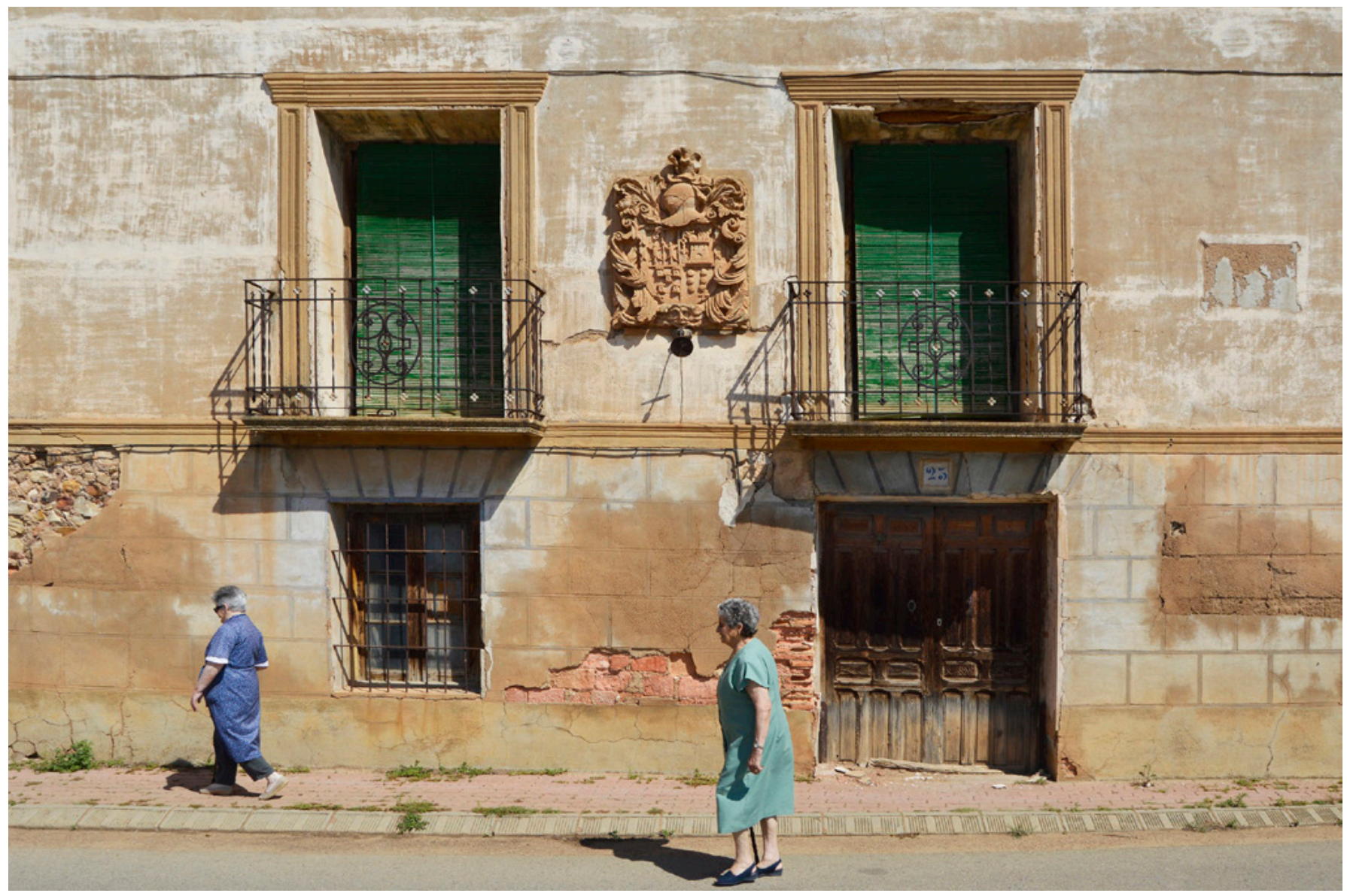

Dos mujeres caminan frente a una casa solariega en Used, un municipio de apenas 250 habitantes en la provincia de Zaragoza | foto Alberto Sánchez Sánchez

Homo se hizo popular fue precisamente porque Borja es una cabecera comarcal de cinco mil habitantes, con título de ciudad desde 1438, y que cuenta con un centro de investigación local. En muchos otros municipios el trabajo de mujeres como Cecilia, con resultados más o menos desafortunados, pasa desapercibido. Y también parece pasar desapercibido el hecho de que la despoblación rural implique que cada vez hay menos personas que se encarguen de hacer este trabajo y que aquellas que lo siguen realizando lo hacen en unas condiciones de precariedad creciente.

A pesar de que no existe un registro exhaustivo del patrimonio rural español a nivel nacional, un análisis de la Lista Roja del Patrimonio de la asociación Hispania Nostra, que recoge bienes en peligro de desaparición, permite una primera aproximación a la magnitud del pro- blema. La gran mayoría de las propiedades incluidas en la Lista (elaborada por un comité científico que revisa las candidaturas enviadas por particulares, asociaciones e instituciones) se encuentran en pequeñas pedanías, aldeas o pueblos. En las provincias de Zaragoza y Guadalajara, por ejemplo, más del $70 \%$ de las propiedades en la Lista Roja están en municipios de menos de quinientos habitantes, cifra similar a la de otras provincias del interior como Cuenca, Palencia, León o Zamora. Así, mientras que la falta de desarrollo económico durante el siglo XX ha permitido a muchos pequeños municipios conservar de forma notable sus bienes patrimoniales, tanto tangibles como intangibles, la despoblación causada por esta misma falta de desarrollo está poniendo en peligro la conservación del patrimonio. Este fenómeno es evidente y especialmente dramático en aquellos municipios que se despoblaron por completo 


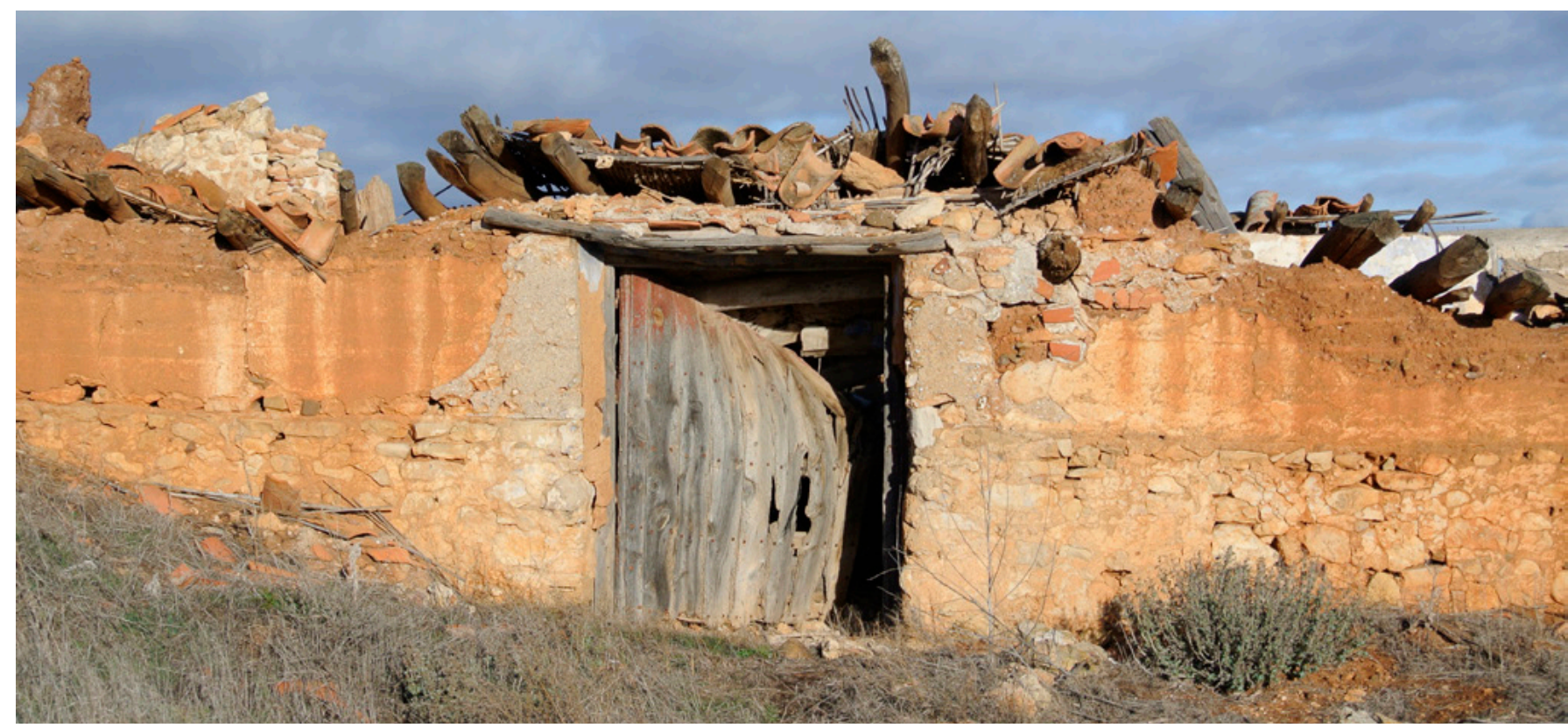

Edificios abandonados en la Venta de Bruno, antigua parada en el Camino Real de Madrid a Barcelona en el término municipal de Used (Zaragoza) | foto Alberto Sánchez Sánchez

durante el s. XX, particularmente en áreas montañosas de la España interior. La segunda gran oleada de despoblación que se está produciendo actualmente amenaza con convertir zonas que hasta ahora habían sido relativamente viables económicamente en un gran desierto poblacional, carente de habitantes que conserven su vastísimo patrimonio cultural.

Mirar más allá del Ecce Homo implica no solamente reconocer y evaluar este fenómeno, sino también entender sus posibles implicaciones y las oportunidades que existen a nivel político y legislativo para abordarlo. Ciertamente, parece difícil que puedan corregirse de forma sencilla o inmediata las condiciones de precariedad de la llamada "España vaciada," y tampoco parece factible un cambio de modelo en el sostenimiento del patrimonio rural que profesionalice la gestión e intervención en el mismo con carácter general, por muy deseable que esto pueda parecer a priori. Sin embargo, sí es posible comenzar a evaluar de qué forma las iniciativas legales existentes pueden incorporar el patrimonio cultural a su discurso. Por ejemplo, las políticas de desarrollo rural de la Unión Europea reconocen ya explícitamente la importancia de los agricultores en el mantenimiento del medio ambiente y la necesidad de compensarlos por este trabajo. Parece lógico que este mismo reconocimiento pueda extenderse al papel que los habitantes del medio rural realizan en la conservación del patrimonio cultural. Si no una solución al problema, al menos esta aproximación sí implicaría reconocer de algún modo el trabajo de todas las "cecilias" que, aunque a veces puedan equivocarse, trabajan discreta y continuamente para conservar el patrimonio rural español. En lugar de ridiculizar la fallida restauración del Ecce Homo, es necesario crear mecanismos que reconozcan y apoyen a todas las "cecilias" y les ayuden y asesoren en su importante, desinteresada y valiosa labor. 